\title{
Proceeding
}

Asia Pacific Conference on Performance Analysis of Sport, 21-24 April 2014. Langkawi, Malaysia.

\section{Isolated and combined effect of brisk walking and yoga training on the physiological parameters of sedentary males}

\author{
DR ABDUSSALAM KANNIYAN \\ King Fahd University of Petroleum \& Minerals, Dhahran, Saudi Arabia
}

\begin{abstract}
Kanniyan, A. (2015). Fisolated and combined effect of brisk walking and yoga training on the physiological parameters of sedentary males. J. Hum. Sport Exerc., 9(Proc2), pp.S666-S671. Introduction: Walking is the most natural activity and the only sustained dynamic aerobic exercise that is common to everyone except for the seriously disabled or very frail. Walking is convenient and may be accommodated in occupational and domestic routines (Morris \& Hardman, 1997). Yoga is a philosophy promoting balance between body and mind and harmony between individual and cosmos (Ananda, 2008). Brisk walking increases cardiorespiratory fitness, manages blood pressure, provides better brain power, sleep, reduces stress level \& controls diabetes, lipid level, builds strong bones, reduce stroke, cancer risk and better longevity (Velumany \& Jayalakshmy, 2005). The purpose of the study was to find out the isolated and combined effect of brisk walking and yoga training on the selected physiological variables of sedentary males. Forty males between 16 to 35 ages were selected for the study. They were divided into two groups. Group-1 underwent combined practices of brisk walking and yoga training and group-2 underwent yoga training alone. The duration of training was for a period of eight weeks (four days per week). The selected physiological variables were blood pressure (systolic \& diastolic) respiratory rate and pulse rate. The data were compared using t-tests. The t values for group-1 for systolic pressure, diastolic pressure, pulse rate and respiratory rate were $1.88,4.01,5.06$ and 8.56 respectively and for group-2 the scores were $0.35,0.09$, 0.12 and 0.19 respectively. Conclusion: the systolic blood pressure, diastolic pressure, respiratory rate and pulse rate of the combined group (group-1) significantly reduced than group-1 (isolated group). Keywords: BRISK WALKING, YOGA, SYSTOLIC PRESSURE, DIASTOLIC PRESSURE, PULSE RATE.
\end{abstract}

Corresponding author. King Fahd University of Petroleum \& Minerals, Dhahran, Saudi Arabia

E-mail: salammanu@kfupm.edu.sa

Asia Pacific Conference on Performance Analysis of Sport, 21-24 April 2014. Langkawi, Malaysia.

JOURNAL OF HUMAN SPORT \& EXERCISE ISSN 1988-5202

(c) Faculty of Education. University of Alicante

doi:10.14198/jhse.2015.10.Proc2.04 


\section{INTRODUCTION}

Due to the increased availability of modern equipments and machineries, the tendency to do physical activity getting reduced day by day which ultimately leads to many kinds of hypokinetic diseases (Chandra, 2009). The expense for treatment for the above said diseases are beyond the calculations and it is alarmingly getting high day by day. Even though, doctors and fitness experts are advising to do any kind of physical activities like aerobic activities, resistance training, majority of the normal populations still keep their deaf ear against these kinds of messages. One of the main reasons for the attitude of the majority is the inability to involve in strenuous activities which make them exhausted. People looking to get easy ways to reduce their additional layer of fats and extra calories. Brisk walking is one of the best of its kind which is accessible to any kind of people in all strata of life. Walking is the most natural activity and the only sustained dynamic aerobic exercise that is common to everyone except for the seriously disabled or very frail. Walking is convenient and may be accommodated in occupational and domestic routines (Morris \& Hardman, 1997). Brisk walking is one of the best, safest and most natural forms of exercise. One can, infact walk their way to healthier, stronger cardiovascular system. Brisk walking is an effective exercise for people of all ages and all states and levels of health. What's more, brisk walking increases our sense of well-being. Human beings are actually designed for lengthy, regular walking. Brisk walking is an appropriate activity for home based exercise programs which has greater improvements in pain and greater participation rates than other forms of aerobic exercise, such as running or cycling (Kimberley, 2009). Brisk walking improves cardiovascular fitness by getting the heart to beat faster to send blood rich in oxygen from lungs to the muscles. This makes the functioning of the heart lungs more efficient, besides reducing blood pressure and the resting heart rate. Walking also helps one recover from a heart attack. It improves blood circulation to the arms and legs and gives a feeling of overall wellbeing. It also relieves depression, stress, and anxiety because it releases endorphins; the body's natural tranquilizers. A good brisk walk can stimulate one's thinking level to a better extent (David \& Jerome, 2007). Recent investigations have proved that brisk walking and other related activities will reduce the risk of cardio-vascular diseases and delays early mortality among woman. The brisk walking is beneficial to improve the cholesterol profile, blood pressure and also increase the energy and stamina and prevents weight gain (Gregg et al, 2003).

Yoga is described as the highest control of mind or the deepest absorption of mind. The word yoga is derived from the Sanskrit root'yuj' meaning to bind, join, attach and yoke, to direct and concentrate one's attention on, to use and apply. Yoga was collated, coordinated and systematized by Patanjali-known as father of yoga- in his classical work 'The Yoga Sutras' which consists of 185 terse aphorisms (lyengar, 2008). Yoga is not a religion. It is a philosophy of life based on certain psychological facts, and its aim is the development of a perfect balance between the body and the mind, and harmony between individual and cosmos (Dhanrar, 2004). Whatever our age, yoga can enhance our lifestyle. Learning yoga develops selfdiscipline and can enhance their physical and mental health. Asanas are good for developing coordination and help to improve concentration and memory. Regular practice can enable young people to keep their natural flexibility for many years. It can help teenagers to keep their youthful flexibility and give them the inner strength to say no to negative influences. Older people often find that gentle yoga exercises allow them to retain mobility and may relive problems such as arthritis and poor circulation. Asanas provide the means for people of any age not only to get and stay in shape but also to develop balance, coordination, and a sense of centeredness. It renews, invigorates, and heals the body, stretching and toning the muscles, joints and spine and directing blood and oxygen to the internal organs including the glands and nerves (Krishna, 1998). Here the very purpose of the study was to examine isolated and combined effect of brisk walking and Yoga training on the selected physiological parameters of sedentary males. 


\section{METHODS}

In order to serve the purpose of the study, forty males between 16 to 35 ages were selected for the study. They were sedentary in nature who neither used to do any kind of physical exercises nor played any games on a regular basis. Prior intimation had given to them about the nature of study and types of physical activity that they should have to undergo. They did not have any previous medical history of any critical diseases which prevents them from being the subjects of the study. They were divided into two groups. Group-1 underwent combined practices of brisk walking and yoga training and group-2 underwent yoga training alone. The duration of training was for a period of eight weeks with a schedule of four days per week. For the one hour session in each day, five minutes basic warming up before the beginning of the training program and a five minutes cooling down after the end of activity was also given. Brisk walking was carried out on an average pace of 5 to $6 \mathrm{~km} / \mathrm{hr}$ and yoga training included different yoga trainings for different body components with surya namaskar at the beginning and shavasana at the end even after the cooling down. The dependent variables selected for the study were Blood pressure (systolic pressure and diastolic pressure) and Pulse rate. Standard equipments (Omron Pressure monitor and pulse counter) were used to gather the relevant data. Pre-test and post-test was done for each group. The obtained values were compared using t-ratio.

\section{ANALYSIS OF THE DATA AND RESULTS OF THE STUDY}

After taking the data, it was analyzed using proper statistical tools. The results of the study are given follows.

Data regarding the values of Blood Pressure (systolic pressure) is given below in Table-1.

Table 1. Systolic Blood Pressure (Pre-test and Post-test Data)

\begin{tabular}{llllll}
\hline Group & Test & Mean & SD & MD & 't' \\
\hline Group-1 & Pre test & 123.3 & 6.5 & & \\
& Post test & 120.1 & 5.1 & 2.90 \\
Group-2 & Pre test & 123.4 & 8.085 & & \\
& Post test & 124.1 & 7.280 & 1.9 & 1.11 \\
\hline
\end{tabular}

Significant at 0.05 level

Table 1 shows that the Mean of the Pre-test for Group-1 (combined group) was 123.3 and Mean of the Post-test was 120.1. The Pre-test score of Group-2 was 123.4 and Post-test score of Group-2 (isolated group) was 124.1. The Standard Deviation score of Group-1 for Pre-test was 6.5 and Post-test was 5.1. The Standard Deviation score of Group-2 was 8.085 (Pre-test) and was 7.280 for Post-test. The Mean difference score of Group-1 was 2.90 and for Group-2 it was 1.9. The t-value of Group-1 (combined group) was 2.22 where the t-value for the isolated group was 1.11 . 
For systolic pressure, the Mean difference of Group-1 is 2.90 and for Group-2 the MD score is 1.90 . The tvalue of Group-1 (combined group) is 2.22 which is higher than the t-value of isolated group (Group-2) which was 1.11. This result indicates that the training of Group-1 (combined group with brisk walking and yoga training) has more significant impact or result than the isolated group (Group-2) with Yoga training alone.

Details of data regarding Diastolic Blood pressure of both groups (Group-1 and Group-2) for Pre-test and Post-test data are given below in Table 2.

Table 2. Diastolic Blood Pressure (Pre-test and Post-test Data)

\begin{tabular}{llllll}
\hline Group & Test & Mean & SD & MD & 't' \\
\hline Group-1 & Pre test & 78.1 & 3.8 & & 4.32 \\
& Post test & 71.9 & 3.89 & 3.90 & \\
Group-2 & Pre test & 78.2 & 4.8 & & \\
& Post test & 75.1 & 3.77 & 0.93 & 1.09 \\
\hline
\end{tabular}

Significant at 0.05 level

The Mean score of Group-1 for Pre-test was 78.1 and the Post-test score it was 71.9. For Group-2, the Mean score for Pre-test was 78.2 and Post-test score was 75.1. The Standard Deviation (SD) score of Group-2 (Pre-test) was 3.8 and the same for Post-test was 3.89. For Group-2, the SD was 4.8 for Pre-test and the same for Post-test was 3.77. The Mean Difference score of Group-1 was 3.90 and for Group-2 the score was 0.9. The t-ratio of Group-1 was 4.32 and for Group-2 the t-ratio was 1.09.

For Diastolic pressure, the Mean difference of Group- 1 is 3.90 and for Group-2 the MD score is 0.93 . The tvalue of Group-1 (combined group) is 4.32 which is higher than the t-value of isolated group (Group-2) which was 1.09. This result indicates that the training of Group-1 (combined group with brisk walking and yoga training) has more significant impact or result than the isolated group (Group-1) with Yoga training alone.

Details of data regarding Pulse rate of both groups (Group-1 and Group-2) for Pre-test and Post-test data are given below in Table 3 .

Table 3. Pulse rate (Pre-test and Post-test Data)

\begin{tabular}{llllll}
\hline Group & Test & Mean & SD & MD & 't' \\
\hline Group-1 & Pre test & 74.4 & 3.77 & & 4.87 \\
& Post test & 68.9 & 3.15 & 4.1 &
\end{tabular}




$\begin{array}{llllll}\text { Group-2 } & \text { Pre test } & 74.9 & 4.22 & & \\ & \text { Post test } & 72.3 & 4.29 & 1.11 & 0.91\end{array}$

\section{Significant at 0.05 level}

From the Table 3, it can be observed that the Pre-test Mean score of Group-1 is 74.4 and Post-test Mean score is 68.9. The Mean score of Group-2 in Pre-test is 74.9 and the same in Post-test is 72.3. The Standard Deviation (SD) score of Group -1 in Pre-test is 3.77 and Post-test score is 3.15. The SD score of Group-2 in Pre-test is 4.22 and the same in Post-test is 4.29. The Mean Difference score (MD) of Group-1 is 4.1 and MD score for Group-2 is 1.11. The t-ratio for Group-1 is 4.87 and t-ratio for Group-2 is 0.91 .

For Pulse rate, the Mean difference of Group-1 is 4.10 and for Group-2 the MD score is 1.11. The t-value of Group-1 (combined group) is 4.87 which is higher than the t-value of isolated group (Group-2) which was 0.91 . This result indicates that the training of Group-1 (combined group with brisk walking and yoga training) has more significant impact or result than the isolated group (Group-1) with Yoga training alone.

\section{CONCLUSIONS}

From keen observations and systematic analysis of the available data, the following conclusions were drawn.

1. For the selected subjects, the combined brisk walking and Yoga training is more productive and resultive to reduce Systolic Pressure than the Yoga training alone.

2. The combined group showed a significant result in reducing Diastolic pressure of the selected subjects. Hence, it is recommended that a combined practice of brisk walking and yoga training is very useful than Yoga practice alone.

3. For pulse rate also, a combined practice of brisk walking and Yoga training will give more significant result than Yoga training.

\section{ACKNOWLEDGEMENT}

The author expresses unfathomable gratitude to KING FAHD UNIVERSITY OF PETROLEUM \& MINERALS, Dhahran, Saudi Arabia for providing the necessary support and funding to do this piece of research work as part of my research project IN121066.

\section{REFERENCES}

1. American college of sports medicine. (2006). ASCM guidelines for exercise testing and prescription. Baltimore: Lippincott Williams \& Wilkins.

2. Chandrashekharan, K. (2011). Sound health through yoga. Tamil Nadu: Prem kalyan publication.

3. David, Q.T., \& Jerome, E.K. (2007). Physical activity and Health, an interactive approach. Sudbarg, Massachusetts, USA: Jones and Bartlett publishers.

4. Dhanrar, V.H. The effects of yoga and $5 B X$ fitness plan on selected psychological parameters University of Alverta, Edmonton -2004. 
5. lyengar, B.K.S. (2010). Light on pranayama. Noida: H.C. publishers.

6. Krishna, R. (1998). A matter of health integration of yoga and western medicine for prevention and cure. Chennai: East West books Madras.

7. Kimberley, B.B., \& Pargman, D. (2009). The effects of Yoga versus Exercise on stress, anxiety, and depression in older adults. International Journal of Yoga therapy, 19, pp.79.

8. Morris, J.N. \& Hardman, A.E. (1997). Walking to health. Sports Medicine, 23(5), pp.306-32.

9. Velumani, S. (2005). Walking a step towards better Health. Coimbatore: Danvanthiri publishers. 